УДК 69

DOI 10.21661/r-553222

Исматова X.P.

Роль геоинформационной экспертной системы

в задачах интерпретации аэрокосмической информации

\title{
Аннотация
}

В статье рассматривается задача повышения эффективности обработки и интерпретации аэрокосмической информации. С этой целью предлагается использовать методы искусственного интеллекта такие, как распознавание образов, нейронные экспертные системы, геоинформационные технологии. На примере построения геоинформационной экспертной системы для оценки пригодности земель показана методика интеграции совокупности данных и технологий для сокращения времени и повышения достоверности интерпретации результатов обработки спутниковой информации.

Ключевые слова: нейронные экспертные системы, геоинформационные технологии, обработка и интерпретация спутниковой информации.

\section{Ismatova K.R. Role of Geoinformation Expert System in Tasks of Interpretation of Aerospace Information}

\section{Abstract}

The article deals with the problem of increasing the efficiency of processing and interpretation of aerospace information. For this purpose, it is proposed to use artificial intelligence methods such as pattern recognition, neural expert systems, geoinformation technologies. Using the example of constructing a geoinformation expert system for assessing the suitability of lands, a method is shown for integrating a set of data and technologies to reduce time and increase the reliability of interpretation of the results of processing satellite information.

Keywords: neural expert systems, geoinformation technologies, processing and interpretation of satellite information.

И звестно, что неполнота объективных данных по исследуемой территории и наличие априорной неопределённости по предмету исследования в существующих информационных источниках является основной проблемой, мешающей эффективному решению задачи дешифрирования изображений.

В трудно формализуемых задачах интерпретации аэрокосмической информации в условиях неполноты исходной информации и использования интуитивных представлений эксперта-дешифровщика пути принятия решений могут быть различными, но все они будут относиться к использованию теории искусственного интеллекта: распознавание образов, многопараметрическая оптимизация на основе предпочтений и замечаний, методы нечеткого логического вывода, экспертных систем и нейросетевых алгоритмов $[1 ; 2 ; 3 ; 13]$.

В данной статье рассматривается проблема построения гибридной информационной системы аэрокосми- ческого мониторинга для оценки пригодности земли. В основе построения системы используются методы искусственного интеллекта, обработки космических снимков и геоинформационные технологии. Основная идея состоит в построении геоинформационной экспертной системы, которая включает в себя знания из различных предметных областей: результаты обработки спутниковой информации и химического анализа почв, другие физико-географические параметры исследуемой территории.

Математическая постановка задачи построения геоинформаиионной экспертной системы

К новым технологиям, позволяющим анализировать и эффективно использовать априорную экспертную информацию для распознавания и интерпретации аэрокосмических изображений, относятся геоинформационные системы (ГИС). Так как исходная информация исследования природных ресурсов из космоса может характеризоваться различными системами из- 
мерений и формой их представления (как космической, так и наземной), а также отражать различное тематическое содержание, видимо, необходимо обобщить и представить её в единой информационной среде в виде удобном для дальнейшего использования. Такой средой является геоинформационная среда, реализуемая геоинформационными технологиями $[10 ; 11 ; 12]$.

Формально задача ставится следующим образом:

- задаётся, полученная по результату обработки аэрокосмической информации, классификационная карта локальных гео и эколандшафтов на исследуемую

территорию. Карта представлена в контурном виде, где указаны границы разделения объектов по их спектральным яркостным характеристикам $[6 ; 9 ; 10 ; 12]$;

- необходимо указать с заданной степенью достоверности классификационно-легендное отнесение каждого объекта к одному из заданных априори тематических классов и принять решение по оценке состояния классов исследуемых объектов на момент съёмки космического снимка, или по серии снимков, дать оценку развития его состояния. Рассмотрим решение этой задачи при использовании гибридных технологий на примере составления карты пригодности земель.

Постановка задачи:

- пусть в результате классификации изображения получена векторная модель, определяющая контура локальных ландшафтов исследуемой местности по их спектральным характеристикам. Иначе, после процедуры классификации изображения исследуемая местность разделена на элементарные участки по типам локальных ландшафтов (ЛЛ), составляющих множество $\mathrm{V}$ элементарных участков территории $[6 ; 7 ; 8]$;

- пусть в процессе интерпретации полученной векторной модели V участвуют T картографических материалов, представленных в ГИС в электронном векторном формате в виде отдельных тематических слоёв.

Для того, чтобы отобразить в необходимой форме исходную картографическую информацию на данную территорию предполагается, что информация о полезной нагрузке карт, хранимая в памяти компьютера в цифровом виде, будет представлена в виде матрицы $\mathrm{R}$ размерности $\left(\mathrm{M}^{*} \mathrm{~N}\right)$, имеющий вид [3]:

$$
R=\left\|r_{i, j}\right\|, \text { где } i=1, \ldots, M ; j=1, \ldots, .
$$

Каждый элемент матрицы $R$ является вектором параметров, характеризующих каждый $(i, j)$-й элементарный участок листа карты по некоторому $m$-мунабору тематических свойств $(m=1, \ldots, T$; $T$-количество карт, участвующих при описании объекта исследования):

$$
r_{i, j}=\left(r_{i j}^{l}, \ldots, r_{i j}^{T}\right) \text {, }
$$

где природа компонентов векторов $r_{i, j}$ в общем случае при описании задачи принципиальной роли не играет.

Тогда, если задаётся известный набор тематических свойств $\{P n\},(n=1, \ldots, K, ; \leq T)$, по которым необходимо районировать исследуемую территорию и по каждому набору тематических свойств заданы их пороговые границы ограничений, то требуется для каждого
$P_{n}$ по их пороговым ограничениям поставить в соответствие множество $V t \in V,(1 \leq t \leq(M x N))$ элементарных участков земной поверхности (ЛЛ), которые обладают свойством $P_{n}$. То есть, это общая постановка задачи районирования исследуемой территории по некоторому набору тематических свойств, исходя из разбиения территории на локальные ландшафты по их спектральным характеристикам.

Тогда, в случае определения пригодности земель вектор признаков $P_{n}$ задан следующим образом:

$$
\mathrm{Pn}=(\mathrm{PKc}, \mathrm{PKt}, \mathrm{PKw}, \mathrm{PKf}, \mathrm{PKch}, \mathrm{PKn})
$$

где каждый $P K i$ - одно из значений из набора признаков, по которым известно, что каждый признак ранжирован по его пороговым ограничениям. Здесь: по климатическим ограничениям (Kc), по топографическим (Kt), по влажности $(\mathrm{Kw})$, по физическим и химическим свойствам почв (Kf), по солености и щелочности почв (Kn) (табл.1) [5; 9; 14]. Такие таблицы составляют эталонные таблицы знаний для нейронной экспертной системы (НЭС), в нашем случае это таблицы частных оценок почв Азербайджана [5].

На рис.2 приведён пример настройки НЭС по степени засоления (признак PKn), с вводимыми для этого показателя ограничениями (табл. 1).

Нам необходимо настроить НЭС для оценки каждого $(i, j)$-го элементарного участка листа карты на пригодность земли по набору свойств $P n$

\begin{tabular}{|c|c|c|}
\hline \multicolumn{3}{|c|}{ Шкала оченок почв по степени засоления } \\
\hline $\begin{array}{c}\text { Градация } \\
\text { по плотному } \\
\text { остатку по Волобуеву }\end{array}$ & $\begin{array}{c}\text { Ограничения } \\
\text { в промилях }\end{array}$ & $\begin{array}{c}\text { Степень } \\
\text { пригодности }\end{array}$ \\
\hline Не засолена & $<0,10$ & лучшие \\
\hline Очень слабо засолена & $0,10-0,25$ & хорошие \\
\hline Слабо засолена & $0,25-0,50$ & средние \\
\hline Средне засолена & $0,50-1,00$ & низкие \\
\hline Сильно засолена & $1,00-2,00$ & $\begin{array}{l}\text { условно } \\
\text { непригодные }\end{array}$ \\
\hline Очень сильно засолена & $2,00-3,00$ & $\begin{array}{l}\text { условно } \\
\text { непригодны }\end{array}$ \\
\hline
\end{tabular}

Таблица 1

\begin{tabular}{|l|c|l|}
\hline \multicolumn{2}{|c|}{ Шкала оценок почв по степени солонцеватости } \\
\hline $\begin{array}{c}\text { Степень } \\
\text { солонцеватости \% }\end{array}$ & Ограничения \% & $\begin{array}{c}\text { Оценка } \\
\text { пригодности }\end{array}$ \\
\hline несолонцеватые & $<5$ & лучшие \\
\hline слабосолонцеватые & $5-10$ & хорошие \\
\hline среднесолонцеватые & $10-15$ & средние \\
\hline $\begin{array}{l}\text { сильно } \\
\text { солонцеватые }\end{array}$ & $15-20$ & низкие \\
\hline $\begin{array}{l}\text { очень сильно } \\
\text { солонцеватые }\end{array}$ & $20-25$ & $\begin{array}{l}\text { условно } \\
\text { непригодные }\end{array}$ \\
\hline солонцы & $>25$ & $\begin{array}{l}\text { условно } \\
\text { непригодные }\end{array}$ \\
\hline
\end{tabular}

Interactive science | $2(57) \cdot 2021$ 
В настраиваемой НЭС для оценки пригодности земель каждые из соответствующих наборов признаков представлены эталонными таблицами ранжирования по порогам ограничений, следуя системе частных шкал (таблицы типа 1), сгруппированных по типам физико-химических свойств: $K c, K t, K w, K f, K c h, K n$.

Соответственно, согласно условиям ранжирования НЭС должна вынести решение отнесения к одному из классов пригодности земли: (S1,.., S5), (где, S1- лучшие; S2 - хорошие; S3 - средние; S4 - низкие; S5 - условно непригодные).
При такой постановке задачи ниже описывается итеративная процедура выработки решения на основе экологических параметров почв Азербайджана и интеграции данных дистанционного зондирования, НЭС и ГИС [5; 9].

На первом этапе НЭС по системе эталонных таблиц в виде системы частных оценок почв обучается выносить решение по каждому из шести подклассов задания тематических свойств данного региона (рис.3). Решение выносится о принадлежности к одному из классов пригодности $(\mathrm{S} 1, \ldots, \mathrm{S} 5)$ по следующей схеме на примере признака Kn (рис. 2):

Рис.2. Схема обучения нейросетевого алгоритма по эталонной таблице (Kn)

$\mathrm{R}:$ Степень засоления (c)

\begin{tabular}{|c|c|c|c|c|c|c|c|}
\hline \multirow{3}{*}{$\begin{array}{l}\text { Степень засоления } \\
\text { незасоленное }\end{array}$} & \multicolumn{2}{|l|}{ ограничения } & \multicolumn{5}{|c|}{ Выходящие обучающие образць } \\
\hline & & & $\mathrm{S}_{1}$ & $\mathrm{~S}_{2}$ & $\mathrm{~S}_{3}$ & $\mathrm{~S}_{4}$ & $\mathrm{~S}_{5}$ \\
\hline & & & 0 & 0 & 0 & 0 & 0 \\
\hline слабозасоленное & & & & & & & \\
\hline среднезасоленное & & & & 0 & 0 & 0 & 0 \\
\hline & & & 0 & 0 & 1 & 0 & 0 \\
\hline сильнозасоленное & & & 0 & 0 & 0 & 0 & 0 \\
\hline Очень сильнозасоленное & & & 0 & 0 & 0 & 0 & 0 \\
\hline
\end{tabular}

Обучающие пары

Подобным образом, НЭС обучается по всем эталонным таблицам (рис. 2).

Тогда, показывая НЭС всевозможные варианты значений признаков в рамках порогов ограничений по каждой к -ой эталонной табличе (в нашем случае $\kappa=1 \ldots, 6)$ на выходе имеем матрицы оценок $\Gamma^{\kappa}$ (рис. 2):

$$
\Gamma^{\kappa}(i, j)=\left\|\left(q_{u, v}^{k}\right)\right\|, q_{u, v}^{k} \in[0,1],
$$

где $(\mathrm{u}, \mathrm{v})$ координаты значений в таблице $\Gamma^{k}$, ответ 1-означает, что по набору признаков $\mathrm{P}_{\text {Кn }}$ (также по остальным) соответственно их порогам ограничений выносится решение о принадлежности к одному из классов пригодности и 0 - в противном случае, k- количество вариантов.

В процессе обучения для фиксированной пары координат $(i, j)$ элемента карты $r(i, j)$ выносится решение отнесения к классу пригодности $\mathrm{S}_{\mathrm{w}} \in\left(\mathrm{S}_{1}, \ldots, \mathrm{S}_{5}\right)$ по функции принадлежности $\mu_{w}(u v)$ если:

$$
\mu_{w}(i, j)=\max \mu_{u, v},\left(\Gamma^{w}\right),
$$

где $\mu_{u, v}\left(\Gamma^{w}\right)=\frac{1}{k} \sum_{i=1}^{k} w_{u, v}^{k} q_{u, v}^{k}, w_{u, v}^{k}-$ коэффициенты относительной важности по кму варианту отнесения к классам $\left(\mathrm{S}_{1}, \ldots, \mathrm{S}_{5}\right)$, вычисляемые как веса нейронной сети, которые хранятся в базе знаний [3].

Следовательно, если НЭС выносит решение по элементу карты с координатами $i, j$, то это означает, что по набору признаков Pn по пересечению u - ой строки и V-го столбца значения суммы эталонных таблиц, полученных при обучении НЭС имеется максимальное количество голосов по оценке пригодности (рис.3).
Все шесть нейронных сетей имеют пять узлов вывода и пять возможных выводных обучающих образцов. Во время обучения, сети «учились» генерировать один из образцов вывода по схеме на рис. 3. Полный класс пригодности для элемента карты выносится, например, в следующем виде: S3 Кс. Это означает, что данный регион по климатическим условиям классифицируется как средне пригодный со среднезасоленными почвами.

Таким образом мы обучаем нейронную сеть с экспертной базой знаний для оценки пригодности земель по ряду экспертных оценок свойств почв на исследуемую территорию. В результате в геоинформационной среде формируется совокупность экспертных знаний в виде тематического слоя пригодности земли, что можно выразить следующим образом:

лист карты $R=\left\|r_{i, j}\right\|$ преобразуется в лист карты $R=\left\|S_{w}(i, j)\right\|$.

Следовательно, для оценки пригодности земель, выделенных по космическому снимку в виде карты локальных ландшафтов, мы имеем экспертную карту оценки пригодности земель по набору заданных свойств.

В свою очередь в ГИС две карты (карта локальных ландшафтов и геоинформационной экспертной карты) в результате географической привязки совместимы, так как имеют одну картографическую проекцию. Отсюда с помощью оверлейных операций значительно облегчён сравнительный анализ и эксперт-дешифровщик в упрощённой форме может формировать итоговую карту пригодности земель по оценке каждой ландшафтной структуры. 


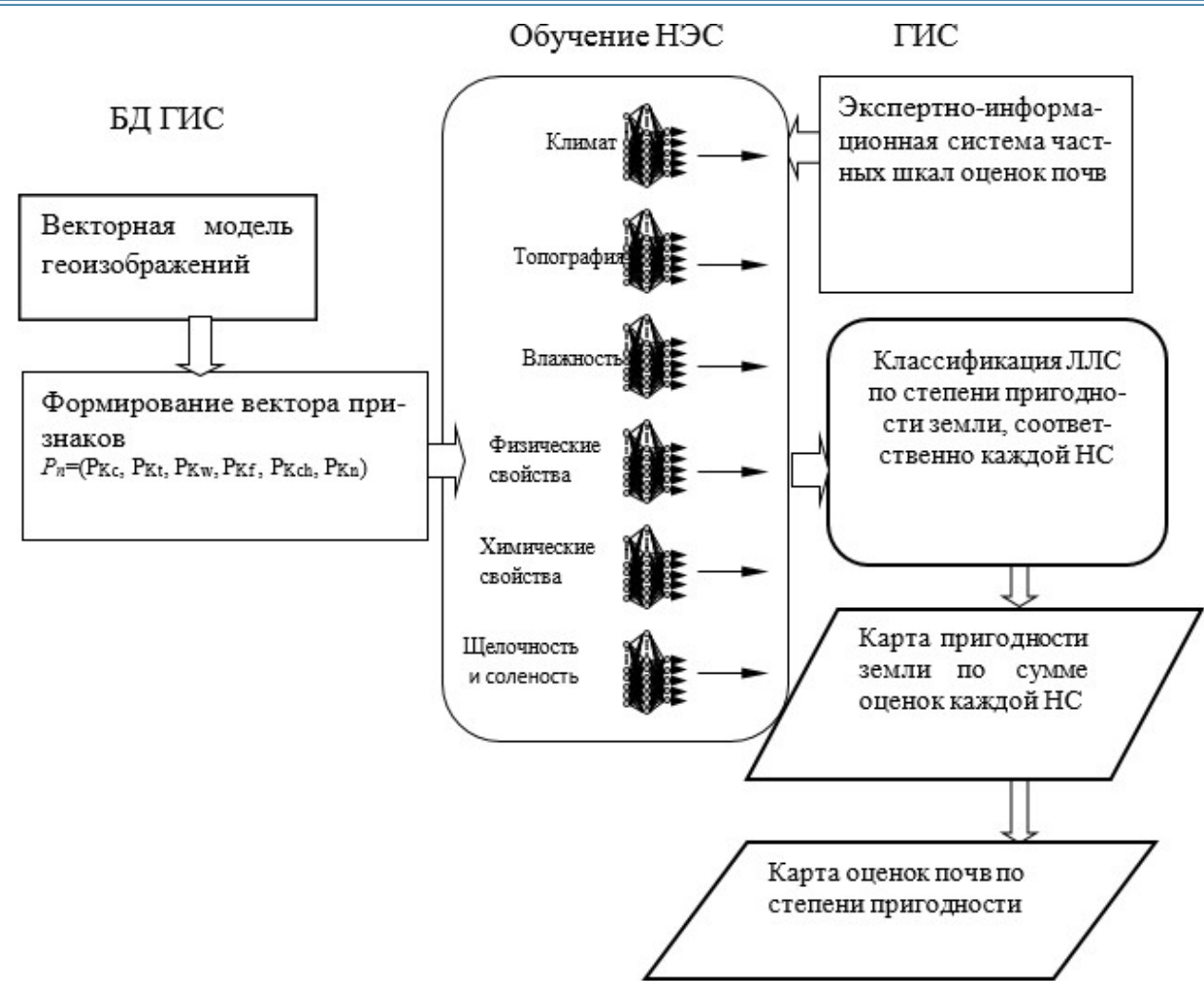

Рис.3. Автоматизированная система оценки пригодности земли, использующая нейронную экспертную систему

Таким образом, представленный метод интеграции НЭС и геоинформационых технологий позволит повысить достоверность и время принятия решений при тематической обработке изображений.

Гибридные технологии позволяют включить в процесс распознавания и интерпретации результата тематической обработки изображений методы искусственного интеллекта. Преимущество такого подхода заключается в предоставлении системе тематического дешифрирования обученных образцов оценочных знаний, на базе которых значительно повышается достоверность интерпретации данных дистанционного зондирования и со- кращается время выполнения процедуры дешифрирования. Не менее важно - сама процедура интерпретации возможна без непосредственного участия экспертов по каждой предметной области, так как их оценки учтены системой эталонных экспертных образцов.

В свою очередь нейросетевые алгоритмы и экспертные системы позволяют выбрать наилучший вариант решения при наличии большого объёма разновидной исходной информации, предоставленной системе дешифрирования изображений экспертами предметной области или полученными в результате мониторинга исследуемой территории.

\section{Литература}

1. Алиев Р.А. Теория интеллектуальных систем и ее применение: учебное пособие для ВУЗов по специальности «Автоматизированные системы обработки информации и управления» / Р.А. Алиев, Р.Р. Алиев. - Баку: Чашыоглы, 2001, - 720 с.

2. Гаврилова Т.А. Базы знаний интеллектуальных систем: учебное пособие / Т.А. Гаврилова, С.В. Хорошевский. СПб.: Питер, 2006. - 382 с.

3. Козлов А.Н. Интеллектуальные информационные системы / А.Н. Козлов. -Пермь, 2013. - 306с.

4. Джарратано Д. Экспертные системы: принципы разработки и программирование / Д. Джарратано, Г. Райли. М.: Вильямс, 2006. - 1152 с.

5. Мамедов Г.Ш. Карта экологической оценки почв Азербайджана и её значения / Г.Ш. Мамедов // Обзорная информация АзНИИНТИ, 1992. - С. 1-25.

6. Исматова Х.Р. Один способ интеграции экспертной базы знаний в систему тематического дешифрирования изображений / Х.Р. Исматова, С.С. Талыбова, С.Н. Абдуллаева. // Сб. научных трудов Национальной Авиационной Академии, посвящённый 70-летию ак. А.М-Дж. Пашаеву. - 2004. - №1. - С. 138-145.

7. Исматова Х.Р. Разработка структуры экологических показателей справочной географической информационной системы / Х.Р. Исматова, С.М. Абдуллаева // Известия АН Азерб. - Баку, 1998. - Т. 18. - №6. - С. $192-197$.

8. Исматова Х.Р. Разработка структуры экологических показателей справочной географической информационной системы / Х.Р. Исматова, С.М. Абдуллаева // Известия НАНА, серия физико-технических и математических наук. - 1998. - Т. 18. - №6. - С. 192-197. 
9. Исматова Х.Р. Нейронная экспертная система для анализа и картирования процессов засоления почв по данным дистанционного зондирования / Х.Р. Исматова // Современные проблемы дистанционного зондирования. №1. - C. 138-145.

10. Исматова Х.Р. Формирование геоинформационной модели развития экологически опасных ситуаций прибрежной территории Каспийского моря. Сборник научных статей «Современные проблемы дистанционного зондирования земли из космоса», ИКИ РАН, Москва, 10-12 ноября 2004,-С. 459-466.

11. Исматова Х.Р. Технология создания кадастра загрязненных земель г. Сумгаита. / Х.Р. Исматова, А. Исламзаде // Современные проблемы дистанционного зондирования. - С. 236-247

12. Черкашина А.К. Базы знаний географических экспертных систем, основанные на естественных классификациях геосистем / А.К. Черкашина, С.В. Солодянкина // Материалы 4 всероссийской научно-методической конференции (Иркутск, 17-19 ноября 2008 г.). - 2008. - С. 93-96.

13. Уотермен Д. Руководство по экспертным системам / Д. Уотермен; Пер. с англ. под ред. Л. Стефанюка. - М.: Мир, 1989. - 388 c.

14. Antonio Di Gregorio. The Land Cover Classification System (LCCS) // Classification Concepts and User: FAO UN, Rome, 1998. -95 c.

\section{References}

1. Aliev, R. A., \& Aliev, R. R. (2001). Teoriia intellektual'nykh sistem i ee primenenie: uchebnoe posobie dlia VUZov po spetsial'nosti "Avtomatizirovannye sistemy obrabotki informatsii i upravleniia"., 720. Baku: Chashyogly.

2. Gavrilova, T. A., \& Khoroshevskii, S. V. (2006). Bazy znanii intellektual'nykh sistem: uchebnoe posobie., 382. SPb.: Piter.

3. Kozlov, A. N. Intellektual'nye informatsionnye sistemy., 306.

4. Dzharratano, D., \& Raili, G. (2006). Ekspertnye sistemy: printsipy razrabotki iprogrammirovanie., 1152. M.: Vil'iams.

5. Mamedov, G. Sh. (1992). Karta ekologicheskoi otsenki pochv Azerbaidzhana i eio znacheniia. Obzornaia informatsiia, 1-25. AzNIINTI.

6. Ismatova, Kh. R., Talybova, S. S., \& Abdullaeva, S. N. (2004). Odin sposob integratsii ekspertnoi bazy znanii v sistemu tematicheskogo deshifrirovaniia izobrazhenii. Sb. nauchnykh trudov Natsional'noi Aviatsionnoi Akademii, posviashchionnyi 70-letiiu ak. A.M-Dzh. Pashaevu, 1, 138-145.

7. Ismatova, Kh. R., \& Abdullaeva, S. M. (1998). Razrabotka struktury ekologicheskikh pokazatelei spravochnoi geograficheskoi informatsionnoi sistemy. Izvestiia AN Azerb, 18, 192-197. Baku

8. Ismatova, Kh. R., \& Abdullaeva, S. M. (1998). Razrabotka struktury ekologicheskikh pokazatelei spravochnoi geograficheskoi informatsionnoi sistemy. Izvestiia NANA, seriia fiziko-tekhnicheskikh i matematicheskikh nauk, T. 18, 6, 192-197.

9. Ismatova, Kh. R. Neironnaia ekspertnaia sistema dlia analiza i kartirovaniia protsessov zasoleniia pochv po dannym distantsionnogo zondirovaniia. Sovremennye problemy distantsionnogo zondirovaniia, 1, 138-145.

10. Ismatova, Kh. R. Formirovanie geoinformatsionnoi modeli razvitiia ekologicheski opasnykh situatsii pribrezhnoi territorii Kaspiiskogo moria. Sbornik nauchnykh statei "Sovremennye problemy distantsionnogo zondirovaniia zemli iz kosmosa", IKI RAN, Moskva, 10-12 noiabria 2004,-S. 459-466.

11. Ismatova, Kh. R., \& Islamzade, A. Tekhnologiia sozdaniia kadastra zagriaznennykh zemel' g. Sumgaita. Sovremennye problemy distantsionnogo zondirovaniia, S. 236.

12. Cherkashina, A. K., \& Solodiankina, S. V. Bazy znanii geograficheskikh ekspertnykh sistem, osnovannye na estestvennykh klassifikatsiiakh geosistem. Materialy 4 vserossiiskoi nauchno-metodicheskoi konferentsii (Irkutsk, 17-19 noiabria 2008 g.), 2008, 93-96.

13. Stefaniuka, L., \& Uotermen, D. (1989). Rukovodstvo po ekspertnym sistemam., 388. Uotermen;; M.: Mir.

14. (1998). Antonio Di Gregorio. The Land Cover Classification System (LCCS). Classification Concepts and User: FAO UN, -95 c. Rome. 